\title{
MR imaging features of spinal pilocytic astrocytoma
}

De-jun She ${ }^{1}$, Yi-ping Lu', Ji Xiong ${ }^{1,3}$, Dao-ying Geng ${ }^{1,2^{*}}$ and Bo Yin ${ }^{1,2^{*}}$

\begin{abstract}
Background: The purpose of this retrospective review is to determine the MR imaging features of pilocytic astrocytoma (PA) in the spinal cord to help neuroradiologists preoperatively differentiate PA from other intramedullary tumors.

Methods: Neuro-oncology database review revealed 13 consecutive patients with a pathological spinal PA diagnosis and availability of preoperative MR imaging. Three patients had preoperative diffusion-weighted MR imaging. Demographics and conventional and diffusion MR imaging records were retrospectively evaluated.

Results: Among 13 cases of spinal PA, six PAs were located in the cervical region, 4 in the cervical-thoracic region, and 3 in the thoracic region. The average length of vertebral segments involved for the tumors were $4.7 \pm 4.6$ segments. Six tumors had associated syringomyelia. Eight PAs were located eccentrically in the spinal cord, and eleven had well-defined margins. Eight tumors (61.5\%) were intermixed cystic and solid. All were contrastenhanced, and $53.8 \%$ of all PAs showed focal nodule enhancement of the solid components. Two PAs showed intratumoral hemorrhages, and only one demonstrated cap sign. The ADC values $(n=3)$ of the tumors were $1.40 \pm$ $0.28 \times 10^{-3} \mathrm{~mm}^{2} / \mathrm{s}$ (min-max: $1.17-1.71 \times 10^{-3} \mathrm{~mm}^{2} / \mathrm{s}$ ).

Conclusions: PA should be considered in the differential diagnosis of intramedullary tumors that occur in the cervical and thoracic regions. Eccentric growth pattern, well-defined margin, intermixed cystic and solid appearance, focal nodular enhancement of solid components and syringomyelia are relatively frequent features. Relatively high ADC values compared with normal-appearing spinal cord parenchyma are common in spinal PA.
\end{abstract}

Keywords: Pilocytic astrocytoma, Spinal cord, Magnetic resonance imaging, Diffusion-weighted imaging

\section{Background}

Pilocytic astrocytoma (PA) is defined as grade I tumor that most frequently occurs in the cerebellum according to the latest World Health Organization (WHO) classification system [1]. PA in the spinal cord is uncommon, comprising only approximately $2-5.2 \%$ of all PAs $[2,3]$. According to data from the CBTRUS, spinal PA accounts for $12.4 \%$ of primary spinal cord tumors in children and adolescents (age $0-19$ years) and $0.8 \%$ in adults (age 20+ years) [4]. Despite its rarity, spinal PA has received much attention due to the significant neurological deficits it causes, typically related to its intramedullary location compared with other PA in other locations of the neuraxis. As a benign and circumscribed

\footnotetext{
*Correspondence: gengdaoying@126.com; 393627969@qq.com

${ }^{1}$ Department of Radiology, Huashan Hospital, Fudan University, 12 Middle

Wulumuqi Road, Jingan District, Shanghai, China

Full list of author information is available at the end of the article
}

astrocytoma, spinal PA rarely invades the surrounding tissue, leads to malignant progression or recurs with complete surgical resection when comparing with other spinal astrocytoma of infiltrative nature. Spinal PA usually represents a clear margin between the tumor and normal spinal cord parenchyma, and therefore, a gross total resection is possible in $50-81 \%$ of the tumors [ 5 , 6]. In addition, spinal PA commonly shows cystic components that are frequently not resected surgically [7]. Therefore, preoperative accurate diagnosis of spinal PA may be useful in the surgical planning and prognosis prediction. Due to the rarity of spinal PA, most of the imaging studies describing this disease are case reports, small case series or literature reviews [7-12]. The purpose of this retrospective study was to analyze MR imaging characteristics that may be helpful in correctly diagnosing spinal PA preoperatively.

C The Author(s). 2019 Open Access This article is distributed under the terms of the Creative Commons Attribution 4.0 International License (http://creativecommons.org/licenses/by/4.0/), which permits unrestricted use, distribution, and reproduction in any medium, provided you give appropriate credit to the original author(s) and the source, provide a link to the Creative Commons license, and indicate if changes were made. The Creative Commons Public Domain Dedication waiver (http://creativecommons.org/publicdomain/zero/1.0/) applies to the data made available in this article, unless otherwise stated. 


\section{Methods}

\section{Patients}

By searching the neuro-oncology database of our hospital between January 2008 and February 2018, 30 consecutive patients were identified for a histopathology-proven spinal PA. Of these 30 patients, 17 patients who did not undergo MR examinations were excluded. Finally, a series of 13 patients with spinal PA ( 8 men and 5 women, average age at diagnosis, 31.6 years; age range, 6-65 years) were enrolled. One patient had postoperative recurrence. The clinical information, imaging and pathologic findings of these patients were reviewed.

All surgical specimens were fixed in 10\% neutral-buffered formalin and stained with hematoxylin and eosin. Histopathologic diagnoses were confirmed according to the latest WHO classification of central nervous system tumors by an experienced pathologist with 8 years of experience (J.X.).

\section{Imaging technique and evaluation}

All patients underwent magnetic resonance imaging (MRI) examinations. MR examinations were acquired using a GE 3.0-T system (GE Medical Systems) with a MR phased array spine coil. The routine imaging sequences included sagittal and axial pre-contrast T1-weighted images (T1WI), sagittal and axial T2-weighted images (T2WI), contrast-enhanced sagittal and axial T1WI and diffusion-weighted images (DWI, single shot, spin-echo, echo-planar imaging sequences), with b-values of 0 and $1000 \mathrm{~s} / \mathrm{mm}^{2}$ in three orthogonal directions. The contrast enhanced T1WI were obtained after the intravenous injection of a standard dose of $0.1 \mathrm{mmol} / \mathrm{kg}$ of gadobenate dimeglumine (MultiHance, Bracco).

All MRI images were retrospectively analyzed in consensus by a fourth-year radiology resident (L.L.) and an experienced neuroradiologist with 10 years of experience (B.Y.) on a PACS workstation monitor. The following imaging findings were recorded: (a) longitudinal location of tumor, defined as the major portion of tumoral involvement among the cervical, thoracic, and lumbar vertebra regions; (b) axial location of tumor (eccentric and central); (c) lesion size, measured in the number of vertebral segments involved; (d) signal intensity on T1WI and T2WI; (e) enhancement characteristics, classified into the following categories based on portions of solid mass enhancement and homogeneity: no enhancement, focal nodular enhancement, diffuse heterogeneous enhancement (heterogeneous enhancement of one-half or more of the solid components of the lesion), and diffuse homogeneous enhancement (homogeneous enhancement of one-half or more of the solid components of the lesion) and patchy enhancement (enhancement of less than one-half of the solid component of the lesion); (f) imaging pattern (intermixture cystic and solid, solid with no cyst, and predominantly cystic); (g) presence of syringomyelia, defined as a cystic dilatation of the central area of the spinal cord, without any contrastenhancement in the wall; (h) intratumoral hemorrhage, defined as hyperintensity on pre-contrast T1WI and hypointensity on T2WI in the tumor; (i) tumor boundary (well-defined or ill-defined); and (j) cap sign, defined as a rim of extreme hypointense signal seen at the distal or proximal pole of the tumor on T2WI, indicating depositions of hemosiderin [13-15]. When diffusion MR imaging was available, a maximum of 3 region of interests (ROI) depending on tumor size (range 1-3, size 10-20 $\mathrm{mm}^{2}$ ) were placed in the contrast-enhanced solid components of the tumors on the apparent diffusion coefficient (ADC) map. In addition, a single ROI was positioned on the normal-appearing spinal cord parenchyma.

\section{Results}

\section{Patient population}

The clinical and radiological features of spinal PA are summarized in Table 1 . The average age at diagnosis was 31.6 years of age (range, 6-65 years) with $76.9 \%$ older than 19 years of age. Eight (61.5\%) patients were male and $5(38.5 \%)$ were female. The course of the disease ranged from 2 months to 5 years. The presenting symptoms were progressive upper limb numbness $(n=4)$, progressive bilateral lower limb weakness $(n=3)$, bilateral lower limb weakness plus bladder dysfunction $(n=1)$, unstable gait $(\mathrm{n}=1)$, neck and back pain $(\mathrm{n}=3)$, and sensory disturbance $(\mathrm{n}=1)$. Seven patients with PA underwent gross total resection, 5 underwent subtotal resection and 1 underwent biopsy only. No patients received postoperative adjuvant radiotherapy or chemotherapy. The mean follow-up was 3.14 years (range, 0.33-7.42 years). One patient died, yielding an overall survival of $76.9 \%$ to date and a 5 -year survival rate of $80.0 \%$.

\section{Imaging}

Of 13 spinal PAs, 6 tumors (46.15\%) were located in the cervical region (Fig. 1), 4 in the cervical-thoracic region, and 3 in the thoracic region. One tumor grew along the cervical region, invading the brain stem. Concerning tumor distribution on axial images, 8 PAs $(61.5 \%)$ were eccentrically located in the spinal cord (Fig. 2) and 5 (38.5\%) were central. The average length of vertebral segments involved for these spinal PAs were $4.7 \pm 4.6$ segments (range, 1-17 vertebral segments). All but two tumors had relatively wellcircumscribed margins. On the preoperative examinations, 8 of $13(61.5 \%)$ were intermixed cystic and solid (Fig. 3). Syringomyelia was evident in six cases (46.2\%). The solid portions of tumors were moderately hyperintense on T2WI and hypointense on 


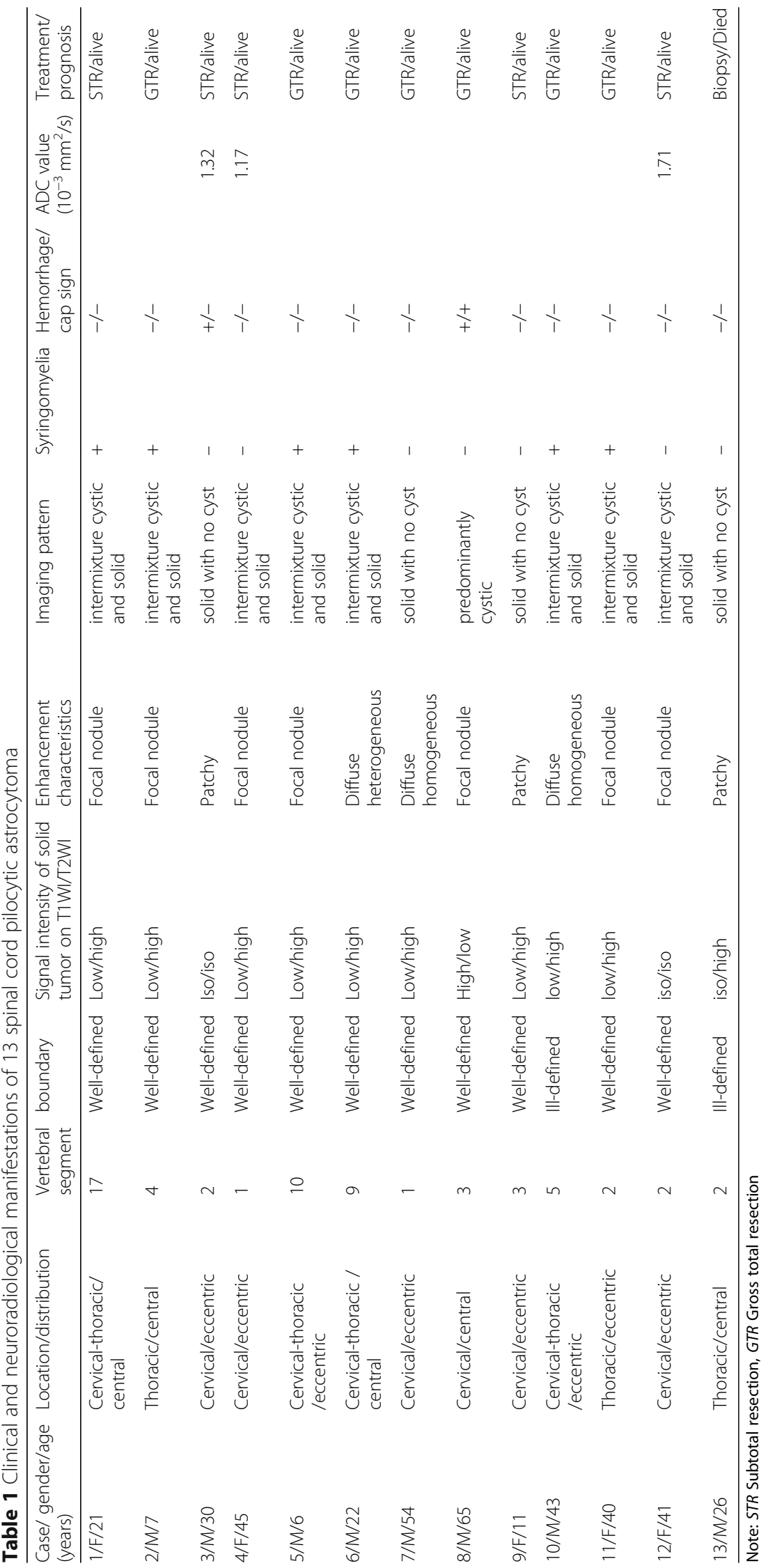




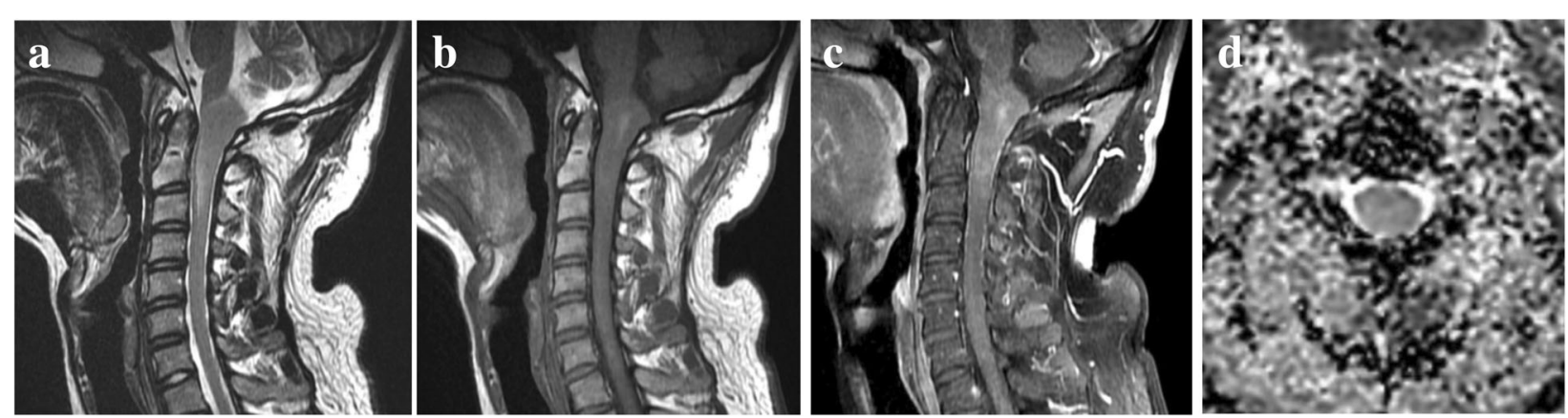

Fig. 1 Cervical PA. a, Preoperative sagittal T2-weighted MR image shows a solid lesion in the cervical region presenting slightly hyperintense signal. Mild peritumoral edema is seen. $\mathbf{b}$, Sagittal T1-weighted MR image shows a high signal intensity region corresponding to hemorrhage in the tumor. c, Sagittal contrast-enhanced T1-weighted MR image shows patchy enhancement of the tumor. $\mathbf{d}$, ADC map shows the solid component shows increased water diffusion (ADC value $=1.32 \times 10^{-3} \mathrm{~mm}^{2} / \mathrm{s}$ )

T1WI. The cystic portions were marked hyperintense on T2WI and hypointense on T1WI. On the contrast-enhanced MR images, 7 of 13 (53.8\%) PAs showed focal nodule enhancement of the solid components of tumor (Fig. 3). In addition, intense enhancement of solid components of tumors was found in 10 of the 13 PAs (76.9\%), whereas mild enhancement was only found in remaining 3 cases. Two spinal PAs (15.4\%) showed evidence of hemorrhage (Fig. 1), and only one case (7.7\%) demonstrated hemorrhage with cap sign.

On DWI, the signal intensity of the solid parts of the tumors was isointense in 3 tumors. ADC values of solid components of tumors were measured in 3 cases. The minimum tumoral ADC values for spinal $\mathrm{PA}$ and normal-appearing spine cord were $1.40 \pm 0.28 \times 10^{-3}$ $\mathrm{mm}^{2} / \mathrm{s}\left(\min -\max : 1.17-1.71 \times 10^{-3} \mathrm{~mm}^{2} / \mathrm{s}\right)$ and $0.79 \pm$ $0.05 \times 10^{-3} \mathrm{~mm}^{2} / \mathrm{s} \quad\left(\min -\max : \quad 0.73-0.83 \times 10^{-3} \mathrm{~mm}^{2}\right.$ /s), respectively (Fig. 1). The ADC values of spinal PA were higher than those of normal-appearing spinal cord, but there were no significant differences $(P=0.05)$.

\section{Discussion}

In this study, we report the preoperative MR imaging findings of spinal PA and describe the diffusion MR imaging metrics of these rare tumors. Although PA occurs most commonly in children and adolescents younger than 20 years, it can be encountered in all age groups ranging from infancy to the eighth decade of life $[2,3$, 8]. Kiernan et al. [16] reported in a large retrospective review of all spinal astrocytomas that a mean age at presentation of spinal PA was 31.9 years with $61 \%$ of patients being male, unlike those in the cerebellum. Among 13 patients with spinal PA in the current study, the mean age was 31.6 years and the male/female ratio was 8:5; this age and sex distribution was consistent with those in previous studies [16].

Spinal PAs are relatively benign tumors characterized by slow growth and late clinical presentation. In one large series in which presenting symptoms were known, the most common symptoms of spinal cord astrocytoma were pain and sensory deficit, followed by motor deficit, which were often of long duration (average 3 years) [5].

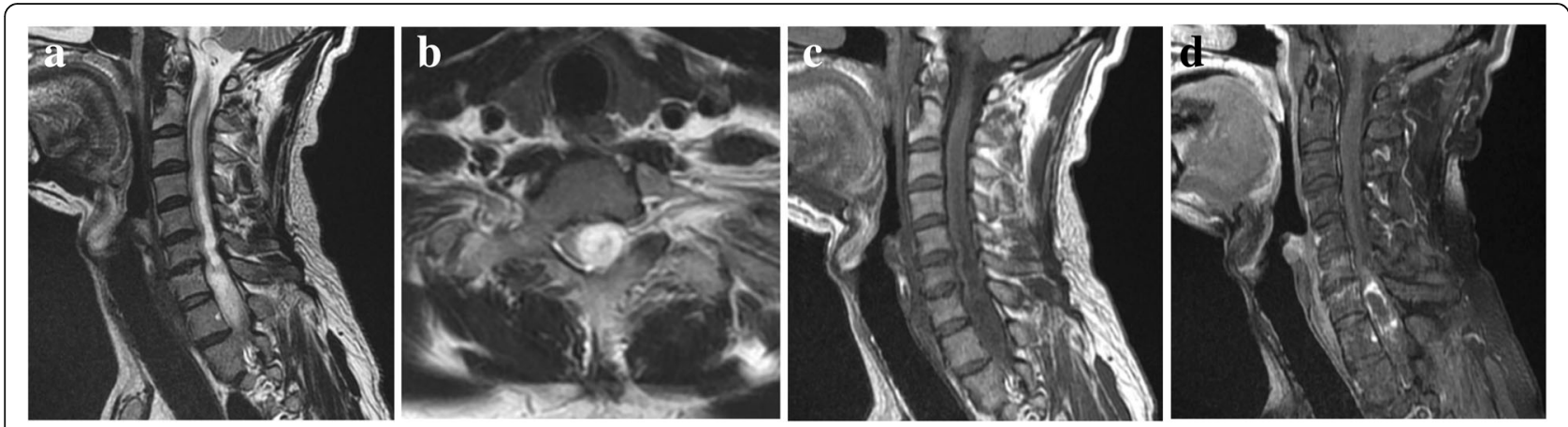

Fig. 2 Cervical-thoracic PA. a, Preoperative sagittal T2-weighted MR image shows a hyperintense lesion in the cervical-thoracic spinal cord with syringohydromyelia. b, Axial T2-weighted MR image shows an eccentric growth pattern. c, Sagittal T1-weighted MR image shows the tumor at hypointense signal intensity. $\mathbf{d}$, Sagittal contrast-enhanced T1-weighted MR image shows diffuse non-homogeneous enhancement of the tumor 

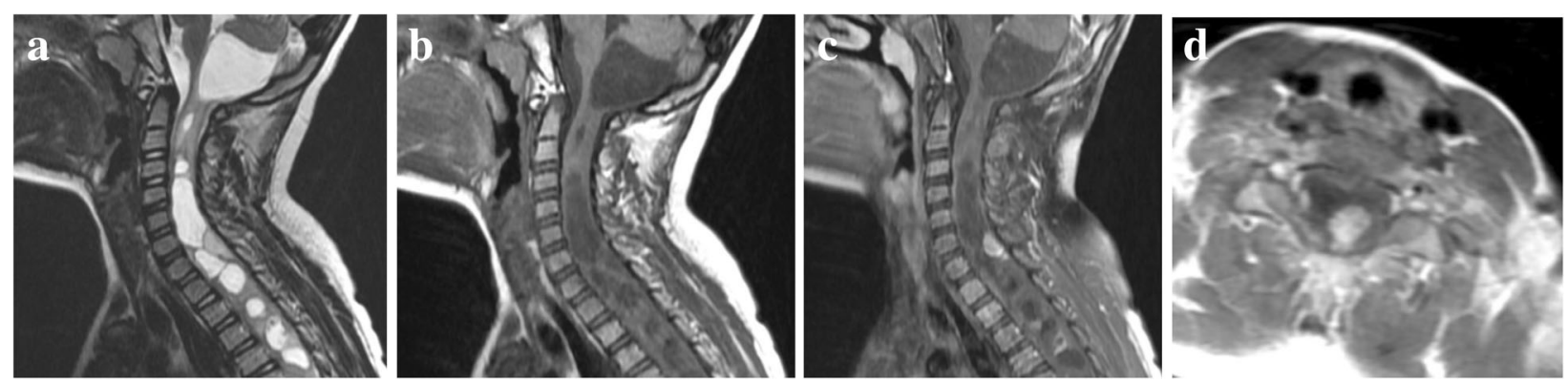

Fig. 3 Cervical-thoracic PA. a, Preoperative sagittal T2-weighted MR image shows a solid-cystic lesion with multi-segmental involved of spinal cord. b. Sagittal T1-weighted MR image shows the solid component of lesion at hypointense signal intensity. c, Sagittal contrast-enhanced T1weighted MR image shows focal nodular enhancement of solid component. $\mathbf{d}$, Axial contrast-enhanced T1-weighted MR image shows that the solid nodule is obviously enhanced. The cystic wall demonstrates no enhancement

Our cohort showed similarities with previous study with pain and sensory deficit (61.5\%) being the most common presentation of spinal PA.

According to the 2016 WHO classification of central nervous system, PA represents grade I tumors histologically [1]. Histologically, PA is a benign tumor of low to moderate cellularity with loosely textured areas, consisting of multipolar cells, microcapsules, and eosinophilic granular bodies, as well as densely fibrillated areas rich in Rosenthal fibers, composed of cells with long bipolar processes and elongated cytologically bland nuclei [17]. Surgery with gross total resection is the preferred treatment and postoperative radiotherapy is not recommended for routine treatment of PA [16]. Spinal PA is remarkable for a favorable outcome with 5- and 10-year overall survival rates of $82-86 \%$ and $74-78 \%$, respectively $[16,18]$. The overall survival rates in our series are comparable.

MRI is the preferred imaging tool for detecting and characterizing spinal cord tumors, especially for intramedullary tumors $[19,20]$. Although there are imaging reports of PA located in the brain [21-23], dedicated imaging studies of intramedullary PA are rare [7-12]. With respect to longitudinal location of spinal PA, 6 tumors in this series were in the cervical region, 4 in the cervical-thoracic region, and 3 in the thoracic region. This location distribution is inconsistent with the findings of Bloomer et al. [19], who found that most astrocytomas reside in the thoracic spine. However, like us, Seo et al. [24] also reported that the cervical region was the most common site of intramedullary astrocytoma. Because PA usually originate from spinal cord parenchyma and not from the central canal, it has been reported that they tend to arise eccentrically within the posterior cord $[25,26]$. In current study, $76.9 \%$ PAs were eccentric type, similar to those in previous reports [7]. This axial location of PA differed from ependymoma, which show a tendency toward a central location with a reported frequency of $91.7-100 \%[13,27]$. In addition, most spinal PA in our study showed a well-defined margin which was similar to that of other PA in other parts of the neuraxis [23], due to its tendency to displace rather than infiltrate neural tissue. In the current study, a mean size of 4.7 vertebral segments for spinal PA was smaller than previous report of a mean size of 7 vertebral segments for astrocytoma [14].

On MRI, the predominant image pattern of PA was a cystic mass with a mural nodule; the solid component of spinal PA is hypointense on T1WI and hyperintense on T2WI [7]. Several studies demonstrated that most PA cyst walls do not enhance while some may enhance intensely $[28,29]$. Spinal PA in our cohort had great propensity for cyst formation, comprising $61.5 \%$ of cases. Although there is no comparable neuroradiologic literature regarding cysts formation within spinal PA, there is evidence that cerebellum PA have a tendency for cyst formation, with an occurrence rate ranging from 44 to $86.7 \%$ [30, 31]. Therefore, our results demonstrated that PA in the spinal cord may present similar intermixed cystic and solid appearance as its intracranial counterparts.

Cerebellum PA are known to enhance, typically intensely [23]. The contrast enhancement of PA is thought to be due to the unique vascular wall of the tumor, in which endothelial cells have open tight junctions and fenestrae that allow contrast material extravasation. The contrast enhancement of spinal PA has been described in two small series studies. Crawford et al. [32] described the preoperative MR imaging findings in 6 spinal PAs of a publication of pediatric spinal cord tumors. The enhancement pattern of spinal PA varied from focal nodular, irregular, no significant enhancement to ring-enhancement. Seo et al. [24] reported that all three PA tumors in their series showed focal or diffuse contrast enhancement. However, a rare case of a non-enhancing spinal pilocytic astrocytoma has been reported in the literature [12]. In this study, all 13 PAs were contrast-enhanced after 
contrast administration, which is consistent with a previous study [24]. Furthermore, we found that focal nodular enhancement, as the predominant contrastenhancement style, was observed in $53.8 \%$ of cases of spinal PA in our series.

Syringomyelia, which refers to ependyma-lined cystic central canal dilatation, is recognized as a common feature of intramedullary spinal cord tumors $[13,19,20]$. Radiologically, these cystic changes are usually located in the rostral and caudal pole of the tumors and do not show any enhancement on contrast-enhanced MR imaging. Clinically, these cysts do not need treatment and commonly resolve after tumor resection. The frequency of syringomyelia in our series of spinal PA is higher than that reported for other intramedullary astrocytomas [13].

Hemorrhage in PA has been described as an uncommon imaging feature that was observed in $2 / 13$ (15.4\%) tumors in our series. According to a previous report, there was only one spinal PA showing spontaneous hemorrhage in a literature review of spinal PA [7]. In a systematic review of PA with an emphasis on hemorrhage, White et al. [33] reported that intratumoral hemorrhage was found in $8 \%$ of cases, a greater frequency than previously thought. Degenerative mural hyalinization of vessels, thin-walled ectatic blood vessels, and dysplastic capillary beds have been speculated as potential causes for hemorrhage in PA [33]. Although hemorrhage does not seem to be a typical presentation, its presence should not exclude the diagnosis of PA. In addition, only one hemorrhage associated with PA seen in the current study was demonstrated as cap sign. Previous studies have demonstrated that a cap sign with hemorrhage, as a characteristic feature of spinal ependymomas, was useful for differentiating intramedullary ependymomas from astrocytomas [13, 14, 19]. The frequency of cap sign in spinal PA in current study is similar to that of spinal astrocytoma and lower than that of spinal ependymoma reported previously [13].

Diffusion-weighted MR imaging has been used in preoperative characterization of spinal lesions [34]. To our knowledge, only a few case reports of diffusion MR imaging characteristics of spinal PA have been reported previously [7, 35]. Maria et al. [35] reported one case of cervical PA had an increase in the ADC value $\left(1.63 \times 10^{-3} \mathrm{~mm}^{2} / \mathrm{s}\right)$. In the three tumors in which ADC values could be reliably measured, we found that the minimum ADC values were $1.40 \pm$ $0.28 \times 10^{-3} \mathrm{~mm}^{2} / \mathrm{s}$, which tended to higher than normal-appearing spinal cord parenchyma. These ADC values of spinal PA are comparable to those of other PA in the brain, and higher than those of ependymomas [36] and high-grade gliomas [30].
Spinal PA should be differentiated from other spinal tumors, including ependymoma, hemangioblastoma, and other spinal astrocytoma. Spinal ependymoma usually occur in lower thoracic and lumbar region, showing a central location of spinal cord [13]. Ependymoma can often display intratumoral hemorrhage, presenting a rim of extreme hypointensity seen at the pole of the tumor on T2WI due to subsequent hemosiderin (cap sign) [27]. In addition, syringohydromyelia is more common in ependymoma whereas contrast enhancement is more heterogeneous than PA $[7,13]$. Hemangioblastoma has the imaging features resembling PA, but the signal void within and around the tumor on MRI is useful for differential diagnosis [14]. Compared with spinal PA, other spinal astrocytoma such as diffuse astrocytoma and anaplastic astrocytoma has an infiltrative nature with poorly defined margin [37].

Our study had some limitations. First, this was a retrospective study without a control group. Second, the number of patients was limited; however, spinal PA is an uncommon tumor, and ours is one of the largest series to date. Third, we had only three patients with PA in whom diffusion-weighted imaging was available. Therefore, conclusions based on the diffusion-weighted imaging study should be interpreted with caution. Future larger studies with emphasis on diffusion-weighted imaging of spinal PA may be of benefit.

\section{Conclusion}

In summary, although spinal PA is rare, it should be considered in the differential diagnosis of spinal cord tumors with intermixed cystic and solid appearance associated with eccentric growth patterns, well-defined margins and focal nodular enhancement after contrast administration. Syringomyelia appears to be a common observation. Relatively high ADC values of the solid portions may distinguish these tumors from high-grade gliomas and ependymomas.

\section{Abbreviations \\ ADC: Apparent diffusion coefficient; DWl: Diffusion weighted imaging; MR: Magnetic resonance imaging; PA: Pilocytic astrocytoma; ROI: Region of interest; T1WI: T1-weighted images; T2Wl: T2-weighted images; WHO: World Health Organization}

\section{Acknowledgements}

Not applicable.

\section{Funding}

This study was funded by the National Natural Science Foundation of Shanghai (Grant No. 18ZR1405700, Grant No. 17411953700, and Grant No. 16410722800), and National Natural Science Foundation of China (Grant No. 81471627 and Grant No. 81501435). The funding sponsors have estimated the feasibility of the study, but have no role in the collection, analysis, or interpretation of the data or in the decision to submit the manuscript for publication. 


\section{Availability of data and materials}

The datasets analyzed in this study are available from the corresponding author on request.

\section{Authors' contributions}

DS, and BY conceived and designed this study. DS, YPL, and JX conducted the study and collected important background data. DS and DG drafted the manuscript. All authors read and approved the final manuscript.

\section{Ethics approval and consent to participate}

The Institutional Review Board of HuaShan Hospital approved this retrospective study and waived the requirement for written informed consent due to its retrospective nature.

\section{Consent for publication}

Not applicable.

\section{Competing interests}

The authors declare that they have no competing interests.

\section{Publisher's Note}

Springer Nature remains neutral with regard to jurisdictional claims in published maps and institutional affiliations.

\section{Author details}

'Department of Radiology, Huashan Hospital, Fudan University, 12 Middle Wulumuqi Road, Jingan District, Shanghai, China. ${ }^{2}$ Institute of Functional and Molecular Medical Imaging, Fudan University, 12 Middle Wulumuqi Road, Shanghai, China. ${ }^{3}$ Department of Pathology, Huashan Hospital, Fudan University, 12 Middle Wulumuqi Road, Jingan District, Shanghai, China.

\section{Received: 3 September 2018 Accepted: 27 November 2018}

\section{Published online: 14 January 2019}

\section{References}

1. Louis DN, Perry A, Reifenberger G, von Deimling A, Figarella-Branger D, Cavenee WK, Ohgaki H, Wiestler OD, Kleihues P, Ellison DW. The 2016 World Health Organization classification of tumors of the central nervous system: a summary. Acta Neuropathol. 2016;131(6):803-20.

2. Burkhard C, Di Patre PL, Schuler D, Schuler G, Yasargil MG, Yonekawa Y, Lutolf UM, Kleihues P, Ohgaki H. A population-based study of the incidence and survival rates in patients with pilocytic astrocytoma. J Neurosurg. 2003; 98(6):1170-4.

3. Johnson DR, Brown PD, Galanis E, Hammack JE. Pilocytic astrocytoma survival in adults: analysis of the surveillance, epidemiology, and end results program of the National Cancer Institute. J Neuro-Oncol. 2012;108(1):187-93.

4. Ostrom QT, Gittleman H, Liao P, Vecchione-Koval T, Wolinsky Y, Kruchko C, Barnholtz-Sloan JS. CBTRUS statistical report: primary brain and other central nervous system tumors diagnosed in the United States in 2010-2014. Neuro-Oncology. 2017;19(suppl_5):v1-v88.

5. Raco A, Esposito V, Lenzi J, Piccirilli M, Delfini R, Cantore G. Long-term follow-up of intramedullary spinal cord tumors: a series of 202 cases. Neurosurgery. 2005;56(5):972-81 discussion 972-981.

6. Eroes CA, Zausinger S, Kreth FW, Goldbrunner R, Tonn JC. Intramedullary low grade astrocytoma and ependymoma. Surgical results and predicting factors for clinical outcome. Acta Neurochir. 2010;152(4):611-8.

7. Horger M, Ritz R, Beschorner R, Fenchel M, Nagele T, Danz S, Ernemann U. Spinal pilocytic astrocytoma: MR imaging findings at first presentation and following surgery. Eur J Radiol. 2011;79(3):389-99.

8. Harraher CD, Vogel H, Steinberg GK. Spinal pilocytic astrocytoma in an elderly patient. World neurosurgery. 2013;79(5-6):799 E797-9.

9. Bansal S, Borkar SA, Mahapatra AK. Hydrocephalus associated with spinal intramedullary pilocytic astrocytoma. Asian journal of neurosurgery. 2017; 12(2):217-9.

10. Schittenhelm J, Ebner FH, Tatagiba M, Wolff M, Nagele T, Meyermann R, Mittelbronn M. Holocord pilocytic astrocytoma--case report and review of the literature. Clin Neurol Neurosurg. 2009;111(2):203-7.

11. Zhao Y, Feng L, Wei Q, Gao L. Adult cervicomedullary pilocytic astrocytoma: a case report. Exp Ther Med. 2015;10(6):2221-3.

12. Larson DB, Hedlund GL. Non-enhancing pilocytic astrocytoma of the spinal cord. Pediatr Radiol. 2006;36(12):1312-5.
13. Kim DH, Kim JH, Choi SH, Sohn CH, Yun TJ, Kim CH, Chang KH. Differentiation between intramedullary spinal ependymoma and astrocytoma: comparative MRI analysis. Clin Radiol. 2014;69(1):29-35.

14. Koeller KK, Rosenblum RS, Morrison AL. Neoplasms of the spinal cord and filum terminale: radiologic-pathologic correlation. Radiographics. 2000;20(6): $1721-49$.

15. Fine MJ, Kricheff II, Freed D, Epstein FJ. Spinal cord ependymomas: MR imaging features. Radiology. 1995;197(3):655-8.

16. Minehan KJ, Brown PD, Scheithauer BW, Krauss WE, Wright MP. Prognosis and treatment of spinal cord astrocytoma. Int J Radiat Oncol Biol Phys. 2009;73(3):727-33

17. Collins VP, Jones DT, Giannini C. Pilocytic astrocytoma: pathology, molecular mechanisms and markers. Acta Neuropathol. 2015;129(6):775-88.

18. Milano MT, Johnson MD, Sul J, Mohile NA, Korones DN, Okunieff P, Walter KA. Primary spinal cord glioma: a surveillance, epidemiology, and end results database study. J Neuro-Oncol. 2010;98(1):83-92.

19. Bloomer CW, Ackerman A, Bhatia RG. Imaging for spine tumors and new applications. Top Magn Reson Imaging. 2006;17(2):69-87.

20. Do-Dai DD, Brooks MK, Goldkamp A, Erbay S, Bhadelia RA. Magnetic resonance imaging of intramedullary spinal cord lesions: a pictorial review. Curr Probl Diagn Radiol. 2010;39(4):160-85.

21. Xia J, Yin B, Liu L, Lu Y, Geng D, Tian W. Imaging features of Pilocytic astrocytoma in cerebral ventricles. Clin Neuroradiol. 2016;26(3):341-6.

22. Gaudino S, Martucci M, Russo R, Visconti E, Gangemi E, D'Argento F, Verdolotti T, Lauriola L, Colosimo C. MR imaging of brain pilocytic astrocytoma: beyond the stereotype of benign astrocytoma. Childs Nerv Syst. 2017;33(1):35-54.

23. Koeller KK, Rushing EJ. From the archives of the AFIP: pilocytic astrocytoma: radiologic-pathologic correlation. Radiographics. 2004;24(6):1693-708.

24. Seo HS, Kim JH, Lee DH, Lee YH, Suh SI, Kim SY, Na DG. Nonenhancing intramedullary astrocytomas and other MR imaging features: a retrospective study and systematic review. AJNR Am J Neuroradiol. 2010;31(3):498-503.

25. Arima H, Hasegawa T, Togawa D, Yamato Y, Kobayashi S, Yasuda T, Matsuyama Y. Feasibility of a novel diagnostic chart of intramedullary spinal cord tumors in magnetic resonance imaging. Spinal Cord. 2014;52(10):769-73.

26. Samartzis D, Gillis CC, Shih P, O'Toole JE, Fessler RG. Intramedullary spinal cord tumors: part l-epidemiology, pathophysiology, and diagnosis. Global Spine J. 2015;5(5):425-35.

27. Kobayashi K, Imagama S, Kato F, Kanemura T, Sato K, Kamiya M, Ando K, Ito K, Tsushima M, Matsumoto A, et al. MRI characteristics of spinal ependymoma in WHO grade II: a review of 59 cases. Spine (Phila Pa 1976). 2017.

28. Beni-Adani L, Gomori M, Spektor S, Constantini S. Cyst wall enhancement in pilocytic astrocytoma: neoplastic or reactive phenomena. Pediatr Neurosurg. 2000;32(5):234-9.

29. Kumar AJ, Leeds NE, Kumar VA, Fuller GN, Lang FF, Milas Z, Weinberg JS, Ater $\mathrm{L}$, Sawaya R. Magnetic resonance imaging features of pilocytic astrocytoma of the brain mimicking high-grade gliomas. J Comput Assist Tomogr. 2010;34(4):601-11.

30. de Fatima Vasco Aragao M, Law M, Batista de Almeida D, Fatterpekar G, Delman B, Bader AS, Pelaez M, Fowkes M, Vieira de Mello R, Moraes Valenca M. Comparison of perfusion, diffusion, and MR spectroscopy between lowgrade enhancing pilocytic astrocytomas and high-grade astrocytomas. AJNR Am J Neuroradiol. 2014;35(8):1495-502.

31. Murakami R, Hirai T, Kitajima M, Fukuoka H, Toya R, Nakamura H, Kuratsu J, Yamashita $Y$. Magnetic resonance imaging of pilocytic astrocytomas: usefulness of the minimum apparent diffusion coefficient (ADC) value for differentiation from high-grade gliomas. Acta Radiol. 2008;49(4):462-7.

32. Crawford JR, Zaninovic A, Santi M, Rushing EJ, Olsen CH, Keating RF, Vezina G, Kadom N, Packer RJ. Primary spinal cord tumors of childhood: effects of clinical presentation, radiographic features, and pathology on survival. J Neuro-Oncol. 2009:95(2):259-69.

33. White JB, Piepgras DG, Scheithauer BW, Parisi JE. Rate of spontaneous hemorrhage in histologically proven cases of pilocytic astrocytoma. J Neurosurg. 2008;108(2):223-6.

34. Plank C, Koller A, Mueller-Mang C, Bammer R, Thurnher MM. Diffusionweighted MR imaging $(\mathrm{DWI})$ in the evaluation of epidural spinal lesions. Neuroradiology. 2007:49(12):977-85.

35. Vargas MI, Delavelle J, Jlassi H, Rilliet B, Viallon M, Becker CD, Lovblad KO. Clinical applications of diffusion tensor tractography of the spinal cord. Neuroradiology. 2008;50(1):25-9. 
36. Gimi B, Cederberg K, Derinkuyu B, Gargan L, Koral KM, Bowers DC, Koral K. Utility of apparent diffusion coefficient ratios in distinguishing common pediatric cerebellar tumors. Acad Radiol. 2012;19(7):794-800.

37. Abd-El-Barr MM, Huang KT, Chi JH. Infiltrating spinal cord astrocytomas: epidemiology, diagnosis, treatments and future directions. Journal of clinical neuroscience : official journal of the Neurosurgical Society of Australasia. 2016;29:15-20

Ready to submit your research? Choose BMC and benefit from:

- fast, convenient online submission

- thorough peer review by experienced researchers in your field

- rapid publication on acceptance

- support for research data, including large and complex data types

- gold Open Access which fosters wider collaboration and increased citations

- maximum visibility for your research: over $100 \mathrm{M}$ website views per year

At $\mathrm{BMC}$, research is always in progress.

Learn more biomedcentral.com/submissions 